\title{
Flame-assisted fuel cells running methane
}

\author{
Kang Wang, Ryan J. Milcarek, Pingying Zeng, Jeongmin Ahn* \\ Department of Mechanical and Aerospace Engineering, \\ Syracuse University, Syracuse, NY 13244-1240, USA
}

\section{Abstract}

In this study, the flame-assisted fuel cell $\left(\mathrm{FFC}^{1}\right)$ was investigated by using methane/ air flames.

The confrontation between FFC temperature and fuel concentration at various conditions was investigated which uncovered the complex behavior of FFCs performance. Variations in fuel/ air equivalence ratio, fuel flow rate and distance between FFC and burner outlet were studied. A critical distance for FFC placement above the burner outlet was uncovered, which has a significant impact on FFC performance. A high power density of $791 \mathrm{~mW} . \mathrm{cm}^{-2}$ was achieved which is comparable to the dual chamber solid oxide fuel cell (SOFC) and single chamber SOFC. The short-term test exhibited good stability of the FFCs under operation despite the presence of carbon formation on the anode surface.

Keywords: Flame-assisted fuel cell; Methane; Solid oxide fuel cell (SOFC); Flame

* Corresponding author. Tel.: 315-443-9309; Fax: +1 3154439099.

E-mail address: jeongahn@syr.edu (J. Ahn).

${ }^{1}$ Flame-assisted Fuel Cell - FFC 
2 Flame-assisted fuel cells (FFCs) are novel energy conversion devices which are based on the 3 combination of a flame with solid oxide fuel cells (SOFCs) [1-3]. In this simple, "no-chamber"

4 setup, the flame serves as a fuel-flexible partial oxidation reformer, while simultaneously

5 providing the heat required for SOFC operation. Compared to traditional dual chamber SOFCs

6 (DC-SOFCs) [4] and single chamber SOFCs (SC-SOFCs) [5], FFCs show several distinguished

7 advantages such as high fuel flexibility, simple setup, rapid startup and shutdown. These

8 characteristics allow FFCs combined with the current combustion systems (coal stoves, boilers,

9 furnaces...) to produce electrical power, thus increasing the system efficiency. For example,

10 FFCs can be integrated into a residential furnace system, transforming the furnace into a FFC-

11 Combined Heat and Power (CHP) system, which will reduce the electricity needed from power

12 plants. This has the potential of offsetting the increased electricity consumption.

13 Recently, several studies have investigated FFCs to determine their potential and applicability

14 for power generation [6-12]. Several simulations have been conducted to confirm the use of DC-

15 SOFCs and FFCs operating on hydrocarbons for use in residential applications [6,7]. A

16 simulation conducted by Wang et al. found that FFC based CHP can achieve a combined

17 efficiency above 90\% [8]. Experimental work has been conducted by Zhu et al. to achieve

18 carbon-free performance and rapid startup with a perovskite oxide anode FFC operating in a

19 propane flame [9]. Additional studies have confirmed that FFCs performance, operating on

20 different hydrocarbon fuels, is significantly influenced by a number of factors including fuel

21 flow rate, equivalence ratio, and distance between the anode and burner outlet $[2,10,11]$. Zhu et

22 al. found that performance was significantly affected by fuel cell temperature, which varied with 
1 the above parameters [11]. Understanding these relationships is essential in order to achieve

2 optimal performance in different environments.

3 As a major constituent of natural gas, methane is widely used in residential fuel-fired

4 furnaces/boilers to provide heat through the combustion process. The investigations of methane-

5 fuel FFCs are especially important for the integration of FFCs-CHP systems. Kronemayer et al.

6 investigated the use of methane flames for FFC operation [3]. However, more work is needed to

7 investigate a wider range of equivalence ratios, fuel flow rates and distances between the burner

8 outlet and the anode surface as well as the effect of carbon coking for methane FFCs. In this

9 study, we present experimental results on the operation of FFCs with methane/air flames and

10 investigate a more extensive examination of the electrochemical behavior of FFCs at the

11 different operating conditions.

\section{2. Experimental apparatus}

\section{$13 \quad 2.1$ Fuel cell fabrication}

14 The anode supported SOFC (AS-SOFC) was selected for this study due to its low ohmic 15 resistance and high thermal shock resistance. The AS-SOFC was prepared by using a co16 pressing technique [13]. SDC $\left(\mathrm{Sm}_{0.2} \mathrm{Ce}_{0.8} \mathrm{O}_{1.9}, \mathrm{NexTech}\right.$ materials $), \mathrm{NiO}+\mathrm{SDC}(60: 40 \mathrm{w} / \mathrm{w}$,

17 NexTech materials) and BSCF $\left(\mathrm{Ba}_{0.5} \mathrm{Sr}_{0.5} \mathrm{Co}_{0.8} \mathrm{Fe}_{0.2} \mathrm{O}_{3-\delta}\right.$, see details of the synthesis of BSCF in $18[14])+\operatorname{SDC}(70: 30 \mathrm{w} / \mathrm{w})$ were used as the electrolyte, anode and cathode materials, respectively.

19 The $\mathrm{NiO}+$ SDC powders were first pressed as substrates; SDC powders were then added onto 20 the substrates and pressed again to form bi-layer pellets, which were fired in air at $1350^{\circ} \mathrm{C}$ for $5 \mathrm{~h}$

21 to complete the densification of the electrolyte layer $(\sim 20 \mu \mathrm{m})$. Then the bi-layer pellets $22\left(\sim 1.25 \mathrm{~cm}^{2}\right)$ with $0.4 \mathrm{~mm}$ thickness were placed in hydrogen at $600^{\circ} \mathrm{C}$ for $3 \mathrm{~h}$ to reduce $\mathrm{NiO}$ to $\mathrm{Ni}$. 
1 The BSCF + SDC was then spray deposited onto the electrolyte surfaces of the sintered bi-layer

2 pellets by using a spraying gun, and then fired at $1000^{\circ} \mathrm{C}$ in nitrogen for $5 \mathrm{~h}$ to form the complete

3 fuel cells with a cathode layer (area: $\sim 0.6 \mathrm{~cm}^{2}$ ).

\section{$4 \quad 2.2$ Characterization}

5 The I-V (current-voltage) method with the 4-probe technique, which can eliminate the effect of

6 the wire resistance, was used to investigate the electrochemical behaviors of the AS-SOFC.

7 Polarization plots, power density curves and current density were created by using a Keithley

82420 sourcemeter interfaced with a computer for data acquisition. A K-type thermocouple

9 attached to the center of the cathode surface and edge of the fuel cell was used to measure the

10 instantaneous temperature of the flame fuel cell. The morphologies of FFCs were examined by a

11 scanning electron microscope (SEM).

\section{$12 \quad 2.3$ Testing setup}

13 Fig.1. is a schematic of the FFC testing system. The fuel cell was glued on a metal disk $(\sim 30 \mathrm{~mm})$

14 using silver paste, which was used to prevent the diffusion of anode gas into the cathode. Silver

15 wire and paste were applied as current collectors for the fuel cell. A quartz tube (ID: 4mm) was

16 used as a burner, which was placed under the fuel cell. The distance between the fuel cell anode

17 and quartz tube outlet was controller by using an electric actuator. Quartz sands (1.4mm, Sigma

18 Aldrich) were filled inside of the quartz tube to achieve better mixing and to avoid flashback. To

19 regulate the flow rate of fuel and air through the burner, two mass flow controllers were

20 employed. LabView data acquisition software was used to control the mass flow controllers and

21 to record the thermocouple data.

\section{3. Results and discussion}


1 Before the fuel cell test, the thermal shock behavior of the fuel cell was checked by placing the

2 fuel cell directly onto the methane flame. The FFC temperature was raised rapidly from $\sim 100^{\circ} \mathrm{C}$

3 to $\sim 680^{\circ} \mathrm{C}$ in 30 seconds and then lowered back to $\sim 100^{\circ} \mathrm{C}$. This process was repeated for 26

4 cycles. Fig. 2 shows the SEM images of the cross-section of the FFC after the heating-cooling

5 test. No cracking was found under the high heating-cooling rates, which indicates the FFC has

6 high thermal shock resistance.

7 The initial test of the FFC was conducted with a premixed equivalence ratio of 6 with a methane

8 flow rate of $400 \mathrm{~mL} \cdot \mathrm{min}^{-1}$. The equivalence ratio $\Phi$ can be calculate by Equation (1),

$$
\Phi=\frac{n_{\text {fuel }} / n_{\text {air }}}{n_{\text {fuel }}^{s} / n_{\text {air }}^{s}}
$$

10 where $n_{\text {fuel }}$ and $n_{\text {air }}$ are the molar flow rates of fuel and air respectively, and $n_{\text {fuel }}^{s}$ and $n_{\text {air }}^{s}$ are

11 the molar flow rates of fuel and air needed for a stoichiometric reaction. The premixed

12 conditions were controlled, but having the flame open to the atmosphere lowers the equivalence

13 ratio of combustion when the atmospheric air is introduced at the burner outlet. As shown in

14 Fig.3, the fuel cell achieved a power density of $\sim 791 \mathrm{~mW} . \mathrm{cm}^{-2}$ and a maximum current density of

$15 \sim 2,300 \mathrm{~mA} \cdot \mathrm{cm}^{-2}$. It should be noted that the power density and current density are the highest

16 reported to date in the literature for FFCs and are comparable to the performances of direct

17 methane fueled DC-SOFC [15] and SC-SOFC [16], even without any optimization. The high

18 power output was contributed to the thin electrolyte layer, the rich fuel atmosphere at the anode

19 and relevant fuel cell temperature $\left(\sim 650^{\circ} \mathrm{C}\right)$. The thin electrolyte and relevant temperature

20 reduces the ohmic losses; at the same time, fuel rich conditions can supply enough fuel to

21 decrease the concentration polarization, especially at the high current loading. Consequently, the

22 total polarization loss was significantly reduced resulting in increased fuel cell performance. 
1 Since the FFC was operated in the open atmosphere, a small disturbance in the flame affects the

2 fuel cell temperature and gas compositions and will be reflected by variations in the power

3 output. That's the reason why the I-V plot in Fig.3 was not smooth compared to other fuel cells,

4 especially at the high current loading. The more obvious variation was also found in the power

5 density curves, especially at high current density load. However, most fuel cells are designed to

6 operate at relatively low current density as an efficient way to avoid the internal losses. The

7 effect of this variation in the FFC can be neglected since the variation at low current density is

8 very small.

9 To achieve a comprehensive understanding, the AS-SOFC based FFC was tested at various 10 conditions to investigate the influence of the interaction between the temperature and fuel 11 concentration on the fuel cell performance. Fig. 4 shows the temperatures of the fuel cell with 12 the methane flow rate ranging from $200 \sim 400 \mathrm{~mL} \cdot \mathrm{min}^{-1}$ at different equivalence ratios with a $13 \quad 2.5 \mathrm{~cm}$ distance between the fuel cell and burner outlet. Since strong reactions or high fuel flow 14 rates can result in safety issues, here, the equivalence ratio was refined from 3 to 10 and the 15 methane flow rates were limited from 200 to $400 \mathrm{~mL} \cdot \mathrm{min}^{-1}$. It is well known that SDC based fuel 16 cells are operated for intermediate temperatures from 500 to $800^{\circ} \mathrm{C}$ [17], so the FFC 17 temperatures were measured to verify the feasibility of operation. In our current setup, it was 18 generally observed that the fuel cell temperature was below $500^{\circ} \mathrm{C}$ when the methane flow is less 19 than $200 \mathrm{~mL} \cdot \mathrm{min}^{-1}$. Thus, only results for methane flow rates from 200 to $400 \mathrm{~mL} \cdot \mathrm{min}^{-1}$ are 20 shown. As we know, the increase of fuel flow rates results in the increased temperature for a 21 certain equivalence ratio due to the increased heat release. At the same time, the temperature

22 increases by reducing the equivalence ratio until the stoichiometric point is reached at a certain 23 fuel flow rate. The trend of the FFC temperature in Fig.4 can satisfy such mechanisms in a 
1 specific equivalence ratio or fuel flow rate. In short, the temperature profile indicates the FFC is

2 suitable for operating at these conditions.

3 Based on the temperature investigation in Fig.4, the FFC testing was performed. Fig.5

4 demonstrates peak power densities of the FFCs with methane flow rates ranging from

5 200 400mL.min ${ }^{-1}$ at different equivalence ratios. For high equivalence ratios (e.g. at 6),

6 obviously, the power densities were improved with increasing methane flow rate. Several

7 reasons give rise to the increase of power outputs: on one hand, the temperature increased by

8 increasing the methane flow rate thus reducing the resistance of the FFC. Additionally, the

9 increase in methane flow rate also supplied sufficient fuel for higher power outputs.

10 Alternatively, for low equivalence ratios with high flow rates, the power didn't increase much

11 even as temperature increased. For example, in contrast to the temperature increasing (about

$1250^{\circ} \mathrm{C}$ ) from the methane flow rates of 320 to $400 \mathrm{~mL} \cdot \mathrm{min}^{-1}$ at an equivalence ratio of 3 , the power

13 densities were almost the same in both conditions. Under this high temperature condition,

14 factors such as insufficient electrochemical activity of the electrode or lack of fuel are unlikely to

15 be the key limitations to the fuel cell output. Instead, it appears that the electronic conductivity

16 of the electrolyte is responsible for the power drop. It is well known that SDC exhibits a mixed

17 (electronic and ionic) conducting characteristic when the fuel cell temperature reaches $650^{\circ} \mathrm{C}$ or

18 higher [18]. Consequently an internal short circuit was introduced by the electronic conductivity,

19 which cut down the power output.

20 By varying the equivalence ratio while fixing the methane flow rate, the fuel cell performances

21 show a more complex behavior. The peak power densities show convex curves. The power

22 increased at first and reached the maximum, then decreased. For example, with the methane

23 flow rate of $240 \mathrm{~mL} \cdot \mathrm{min}^{-1}$, the fuel cell achieved a peak power density of $345 \mathrm{~mW} \cdot \mathrm{cm}^{-2}$ at an 
1 equivalence ratio of 10 , then reached the maximum at $485 \mathrm{~mW} \cdot \mathrm{cm}^{-2}$ and decreased to

$2452 \mathrm{~mW} . \mathrm{cm}^{-2}$ at an equivalence ratio of 3. Combined with Fig.6, it indicates that the fuel

3 concentration plays a key effect on FFC performance drop. Natural convection was used for the

4 oxygen supply at the cathode. If the oxygen supply is limited, this condition could introduce

5 concentration polarization. In order to exclude this possibility, the fuel cell was tested using a

6 dual chamber configuration with the hydrogen flow rate of $100 \mathrm{~mL} \cdot \mathrm{min}^{-1}$ at $650^{\circ} \mathrm{C}$ where the

7 cathode was exposed to the atmosphere (see details about the DC-SOFC in Ref [14]). In this

8 way, the oxygen was supplied only by natural convection. Our results confirm that the

9 maximum current density is $4 \mathrm{~A} \cdot \mathrm{cm}^{-2}$ in the dual chamber configuration. Since the maximum

10 current density of our current FFC testing was only $2.53 \mathrm{~A} . \mathrm{cm}^{-2}$, with the methane flow rate of

$11400 \mathrm{~mL} \cdot \mathrm{min}^{-1}$ and an equivalence ratio of 8 , the oxygen at the cathode is expected to be sufficient.

12 Oxygen will not dominate the fuel cell performance and bring high concentration polarization to

13 the fuel cell. The limited fuel supply for the fuel cell is responsible for the fuel cell performance

14 drop. Before reaching the maximum power density, the FFC performance was most likely

15 dominated by the temperature because maximum current densities didn't exhibit much change or

16 even got smaller. Instead, after that, even with increase of temperature, the fuel concentration

17 took more effect on the FFC performance drop, which was consistent with the decrease of

18 maximum current densities. As we know, too much air mixed with the fuel resulted in less fuel

19 available which results in concentration polarization for the FFC.

20 Fig. 7 shows the change of the FFCs temperature and OCV at an equivalence ratio of 6 (methane

21 flow rate: $400 \mathrm{~mL} \cdot \mathrm{min}^{-1}$ ) as the distance (insert in Fig. 7) between the fuel cell and burner outlet

22 was varied. Variation of the temperature with distance had a concave shape with peak

23 temperatures in the middle. At a distance of $10 \mathrm{~cm}$, the temperature of the fuel cell was low 
$1 \quad\left(\sim 400^{\circ} \mathrm{C}\right)$ because the fuel cell was well above the reaction zone and less heat was transferred.

2 The temperature increased as the distance decreased until it peaked at $\sim 630^{\circ} \mathrm{C}$. At these

3 intermediate distances $(\sim 2.5-4 \mathrm{~cm})$, the fuel cell was inside the reaction zone of the flame and

4 more heat was transferred to the cell. Decreasing the distance below $2.5 \mathrm{~cm}$ resulted in a

5 temperature decrease. As the distance decreased, the fuel cell was primarily exposed to

6 premixed gases with less heat transfer from combustion.

7 A similar pattern was found for the OCV variation with distance. Initially the OCV was very low,

8 only $\sim 0.12 \mathrm{~V}$ at a distance of $10 \mathrm{~cm}$. This result is primarily due to the low fuel concentration of

9 the flame exhaust because very little fuel was present just prior to reaching the fuel cell. As the

10 distance decreased, the $\mathrm{OCV}$ increased to $0.8 \mathrm{~V}$ at a distance of $2.5 \mathrm{~cm}$ due to the fuel rich,

11 incomplete combustion. However, further decrease of distance to $1 \mathrm{~cm}$ resulted in the sudden

12 drop of $\mathrm{OCV}$ from $0.8 \mathrm{~V}$ to $0.11 \mathrm{~V}$. At this 'critical distance', the drop in the OCV can be

13 attributed to the FFC touching the premixed zone. This region, which is close to the burner

14 outlet, contains a higher concentration of unburned fuel and oxygen. The OCV is expected to

15 drop as the oxygen concentration difference between the cathode and anode decreases.

16 To further validate the cause of the low $\mathrm{OCV}$ at distances less than $2.5 \mathrm{~cm}$, methane (flow rate:

$17400 \mathrm{~mL} \cdot \mathrm{min}^{-1}$ ) was premixed with an increasing amount of air, starting at no air flow. The

18 distance from the FFC to the burner outlet was fixed at $1 \mathrm{~cm}$. Fig. 8 shows how the OCV

19 changed as the concentration of air was increased. Initially, having no premixed air resulted in an

20 OCV of $\sim 0.85 \mathrm{~V}$ (temperature: $\sim 450^{\circ} \mathrm{C}$ ). In this condition, the flame is a pure diffusion flame

21 which contains a considerable amount of syngas, resulting in the high OCV. Please note that the

22 methane fuel doesn't attribute to the high OCV significantly due to its low activity at this

23 temperature. To confirm this result, the FFC was tested in a DC-SOFC setup running with pure 
methane. The results obtained confirm that the OCV was only $\sim 0.3 \mathrm{~V}$ at a similar operating temperature.

3 As the air flow increases, the OCV drops rapidly between an air flow rate of $200(\Phi=20)$ and $4450 \mathrm{~mL} \cdot \mathrm{min}^{-1}(\Phi=9)$. Since the equivalence ratio for the ideal methane partial oxidation is 4 , a 5 high OCV was expected, which is contrary to the data obtained under those conditions. It is 6 believed that adding air to the fuel mixture increases the premixed zone which actually decreases

7 the OCV due to lower oxygen partial pressure difference across the cell. By increasing the air

8 flow above $450 \mathrm{~mL} \cdot \mathrm{min}^{-1}$ the OCV decreases further, but at a slower rate. With the fuel cell set 9 at $1 \mathrm{~cm}$, increasing the air flow rate beyond $450 \mathrm{~mL} \cdot \mathrm{min}^{-1}$ did not alter the OCV as much because 10 of the short distance between the cell and burner.

11 Based on results from Fig. 6, the electrical efficiency $(\varepsilon)$ was calculated (shown in Fig.9) based on the method of Michio [2]. $\mathcal{E}$ is defined here as

$$
\varepsilon=\frac{\text { electrical power generated by } \mathrm{FFC}}{\text { heating power of fuel input }}=\frac{\mathrm{P} \cdot \mathrm{A} \cdot \mathrm{V}_{\mathrm{m}}}{\dot{\mathrm{V}} \cdot \mathrm{HHV}}
$$

14 where $\mathrm{P}$ is the peak power density, $\mathrm{A}$ is cathode area of fuel cell, $\dot{\mathrm{V}}$ in $\left(\mathrm{m}^{3} \cdot \mathrm{s}^{-1}\right)$ is the methane 15 flow rate at standard conditions, $\mathrm{V}_{\mathrm{m}}=2.24 \times 10^{-2} \mathrm{~m}^{3} \cdot \mathrm{mol}^{-1}$ is the molar volume at standard 16 conditions, and HHV $=8.89 \times 10^{5} \mathrm{~J}^{\mathrm{mol}} \mathrm{mol}^{-1}[19]$. As shown in Fig.9, in contrast to the condition 17 achieved for the best power out, the best efficiency $(\sim 0.19 \%)$ was achieved at equivalence ratio 18 of 6 with the methane flow rate of $320 \mathrm{ml}_{\mathrm{min}} \mathrm{m}^{-1}$. This value is low. However, if the FFCs are 19 used with current combustion technologies, the remaining fuel and heat is recoverable for 20 various heating applications or further power generation. This setup could improve the total 21 system efficiency while also providing electricity to run external components. Furthermore, it 22 should be noted that the actual flame in the current setup can even serve a FFC 10 times larger 23 than the current FFC, which means the efficiency could be increased. 
1 The short-term test at a current density loading of $200 \mathrm{~mA} \cdot \mathrm{cm}^{-2}$ was performed, with the FFC

2 operated on a methane/air flame at an equivalence ratio of 6 with a methane flow rate of

$3320 \mathrm{~mL} \cdot \mathrm{min}^{-1}$. As shown in Fig.10, in response to atmospheric variation, there was a small

4 oscillation in the power output. However, there was no obvious performance deration which

5 illustrates the good stability of FFCs in a short term. Carbon coking for FFCs is a well-known

6 problem for $\mathrm{Ni}$ based anodes. Compared to the DC-SOFC, where carbon coking due to the $\mathrm{Ni}$

7 catalyst is observed, FFCs are also known to have soot formation from the flame due to the

8 formation of $\mathrm{C}_{2} \mathrm{H}_{2}$ [20-22]. In our testing, the carbon layer formed quickly on the anode surface

9 when pure methane was used without pre-mixed air. It is believed that the rapid formation of the

10 carbon layer is due to both the promotion of $\mathrm{Ni}$ catalyst to coking and the soot formation from

11 flame.

12 By premixing air and methane, soot formation and coking was suppressed (see Fig.11). Figure

13 11(a) and (b) shows the SEM image of the anode surface before and after the short term testing.

14 Although carbon particles were observed on the anode after the short term test, the carbon layer

15 did not cover the anode significantly, which allowed gas diffusion to continue. Figure 11(c) also

16 confirms that coking in the cross section was negligible after the short term testing. As a result,

17 the performance of the FFC was not significantly affected during the short term test. However, if

18 testing continued, soot formation is expected to continue with time, which would be detrimental

19 to the FFCs performance. In addition, coking due to the Ni catalyst will also become more

20 significant due to trace amount of hydrocarbons. In a future study, more work is needed to

21 reduce soot formation and carbon coking.

\section{4. Conclusions}


1 In conclusion, the FFC exhibits a high performance of $791 \mathrm{~mW} . \mathrm{cm}^{-2}$ with the methane/air flame.

2 The FFC shows a complex behavior in response to variations in temperature, fuel flow rate and

3 equivalence ratio. The temperature tends to dominate the power output at high equivalence

4 ratios. Alternatively, the fuel concentration dominated at low equivalence ratios. At high

5 temperatures, the mixing conductivity of SDC also had an effect on the power output. The

6 distance between the FFC and burner outlet has a significant impact on the FFCs OCV and

7 operating temperature. When the FFC reaches the critical distance, the OCV drops rapidly due

8 to unreacted oxygen. While operating within this critical distance, the FFCs OCV is highly

9 dependent upon the total air flow rate. Although the short term test shows good stability of FFC

10 operation, carbon is still present at the anode surface, but its formation is greatly suppressed by

11 premixing the methane and air. Future work should focus on addressing carbon coking and soot

12 formation in long term testing. Application of FFCs to combustion technologies will require

13 optimization of the FFCs performance. The optimization process is complex and requires an

14 investigation of the equivalence ratio, total fuel flow rate, operating temperature and distance

15 from the burner to the FFC. Given the simplicity of FFC, there is potential to combine FFC with

16 current combustion technologies to provide efficient CHP systems.

\section{Acknowledgement}


References

[1] M. Horiuchi, S. Suganuma, M.Watanabe, J. Electrochem. Soc. 151 (2004) 1402-1405.

[2] K. Wang, P.Y. Zeng, J. Ahn, Proc. Combust. Inst.33 (2011) 3431-3437.

[3] H. Kronemayer, D. Barzan, M. Horiuchi, S. Suganuma, Y. Tokutake, C. Schulz, W. G. Bessler, J. Power Sources 166 (2007) 120-126.

[4] B.C.H. Steele, P.H. Middleton, R.A. Rudkin, Solid State Ionics 40/41 (1990) 388-393.

[5] Z.P. Shao, S.M. Haile, J. Ahn, P.D. Ronney, Z. Zhan, S.A. Barnett, Nature 435 (2005) 795-798.

[6] V. Liso, A.C. Olesen, M.P. Nielsen, S.K. Kær, Energy, 36 (2011) 4216-4226.

[7] S. Farhad, F. Hamdullahpur, Y. Yoo, Int. J. Hydrogen Energy, 35 (2010) 3758-3768.

[8] Y. Wang, Y. Shi, M. Ni, N. Cai, Int. J. Hydrogen Energy, 39 (2014) 5996-6005.

[9] X. Zhu, B. Wei, Z. Lü, L. Yang, X. Huang, Y. Zhang, M. Liu, Int. J. Hydrogen Energy 37 (2012) 8621-8629.

[10] K. Wang, R. Ran, Y. Hao, Z. Shao, W. Jin, N. Xu, J. Power Sources 177 (2008) 33-39.

[11] X.B. Zhu, Z. Lü, B. Wei, X.Q. Huang, Z.H. Wang, W.H. Su, J. Electrochem Soc 157 (2010) B2838-B2843.

[12] L. Sun, Y. Hao, C. Zhang, R. Ran, Z. Shao, Int. J. Hydrogen Energy 35 (2010) 7971-7981.

[13] C.R. Xia, M.L. Liu, Solid State Ionics 144 (2001) 249-255.

[14] K. Wang, R. Ran, Z.P. Shao, J. Power Sources 170 (2007) 251-258.

[15] B. Huang, X.F. Ye, S.R. Wang, H.W. Nie, J. Shi, Q. Hu, J.Q. Qian, X.F. Sun, T.L. Wen, J. Power Sources 162 (2006) 1172-1181.

[16] Z.P. Shao, J. Mederos, W. C. Chueh, S. M. Haile, J. Power Sources 162 (2006) 589-596. 
14

15

16

17

18

19

20

23

24

21

22

[17] B.C.H Steele, Solid State Ionics 129 (2000) 95-110.

[18] X.G. Zhang, M. Robertson, C.De^ces-Petit, W. Qu, O. Kesler, R. Maric, D. Ghosh, J. Power Sources 164 (2007) 668-677.

[19] D.R. Lide, CRC Handbook of Chemistry and Physics, 90 ed., CRC Press, Boca Raton, Florida, USA, 2009.

[20] E.R. Ramer, J.F. Merklin, C.F. Sorensen, T.W. Taylor, Combust. Sci. and Tech. 48 (1986) 241-255.

[21] S.J. Harris, A.M Weiner, Combust. Sci. and Tech. 32 (1983) 267-275.

[22] F. Xu, K.C. Lin, G.M. Faeth, Combust. Flame 115 (1998) 195-209.

(1)

11

2

3

14

5

6

7

8

19

0




\section{Figure Captions}

$3 \quad$ Figure 1: Schematic of experimental setup for FFC testing

$4 \quad$ Figure 2: The cross-sectional morphologies of FFC after testing

5 Figure 3: Polarization and power density curves of FFC at the methane flow rate of 400mL.min ${ }^{-1}$ $6 \quad$ with the equivalence ratio of 6.

7 Figure 4: FFC temperatures as functions of equivalence ratio and methane flow rate.

8 Figure 5: Peak power densities of FFC as functions of equivalence ratio and methane flow rate.

9 Figure 6: Peak current densities of FFC as functions of equivalence ratio and methane flow rate.

10 Figure 7: OCVs as a function of distance between fuel cell and burner outlet at an equivalence 11 ratio of 6 with the methane flow rate of $400 \mathrm{~mL} \cdot \mathrm{min}^{-1}$.

12 Figure 8: OCVs as a function of air flow rate with a methane flow rate of $400 \mathrm{~mL} \cdot \mathrm{min}^{-1}$.

13 Figure 9: Electrical efficiency of FFC based on the results in Fig.6.

14 Figure 10: Short term test of FFC with a current density loading of 200mA.cm ${ }^{-2}$.

15 Figure 11: SEM morphologies of the anode: (a) surface before testing; (b) surface after short term testing; and (c) cross section after short term testing.

17 


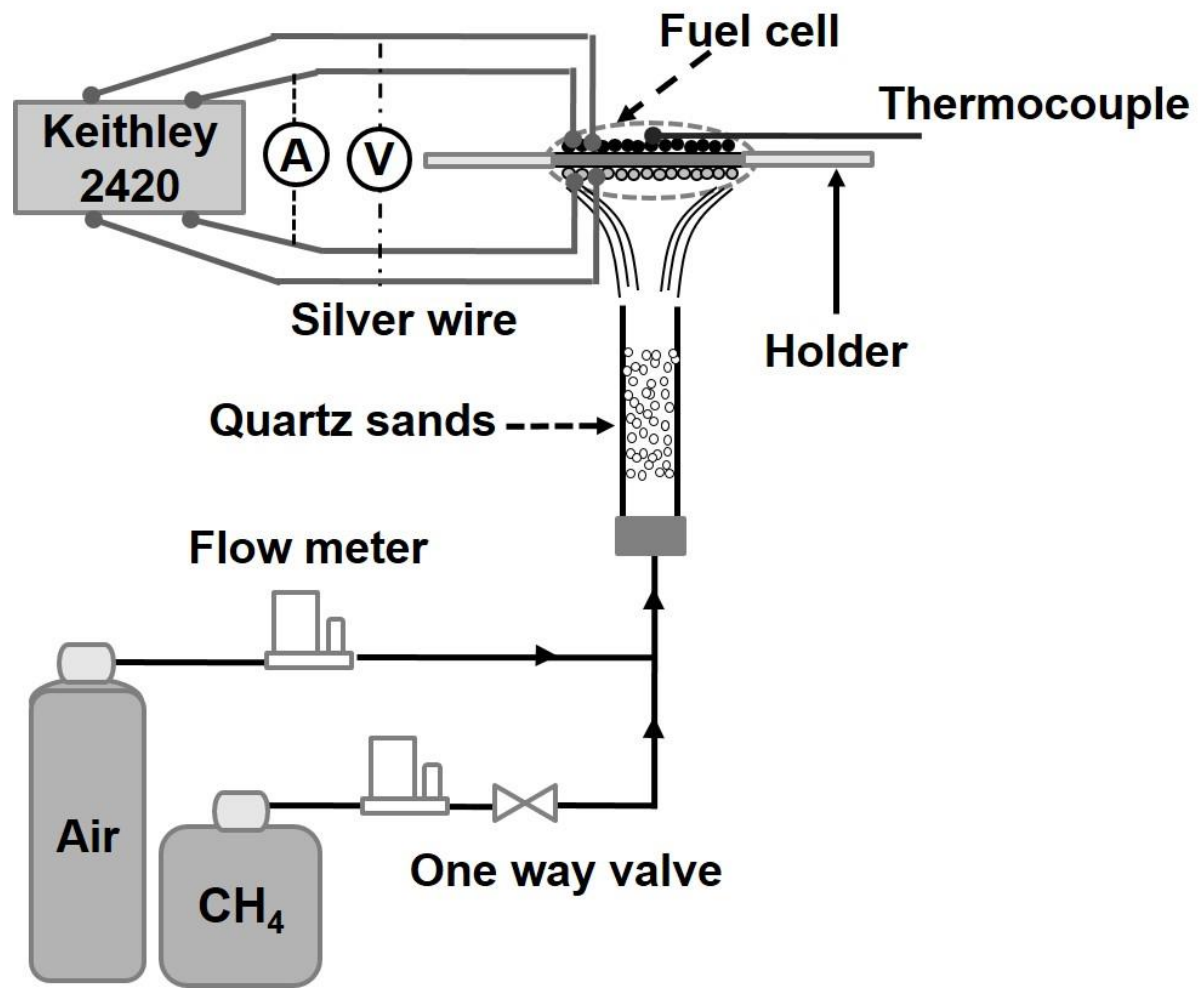

Figure 1: Schematic of experimental setup for FFC testing 


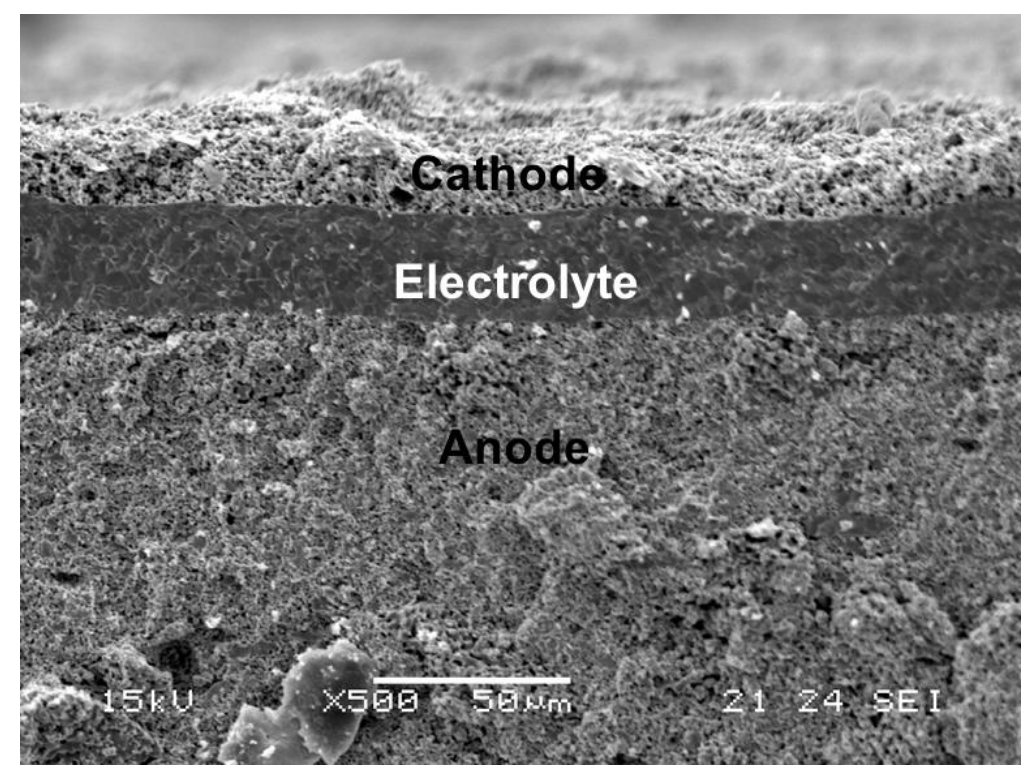

Figure 2: The cross-sectional morphologies of FFC after testing 


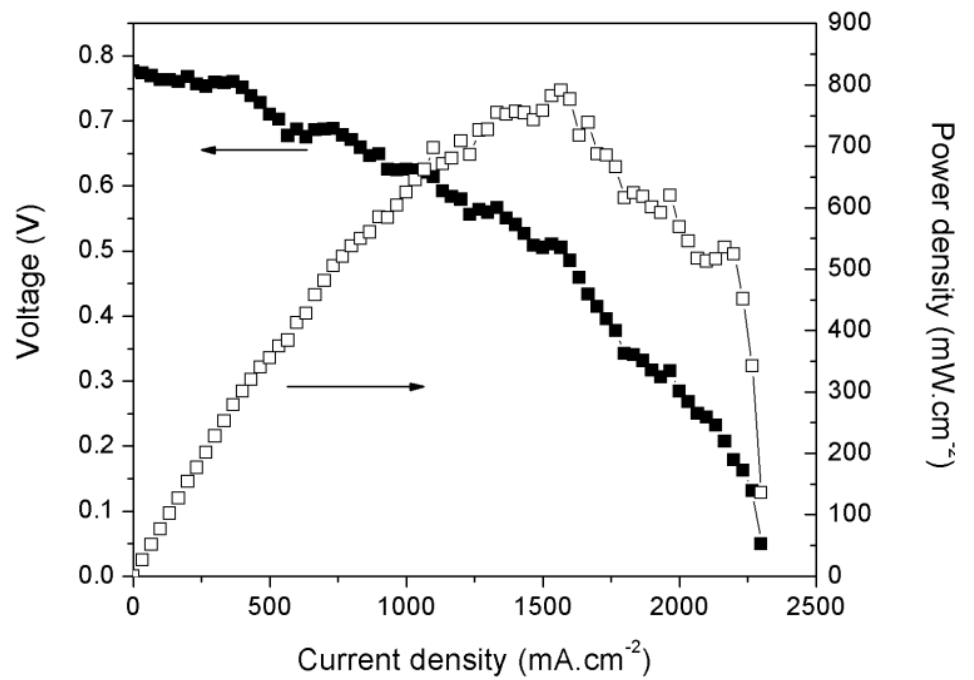

Figure 3: Polarization and power density curves of FFC at the methane flow rate of 400mL. $\mathrm{min}^{-1}$ with the equivalence ratio of 6 . 


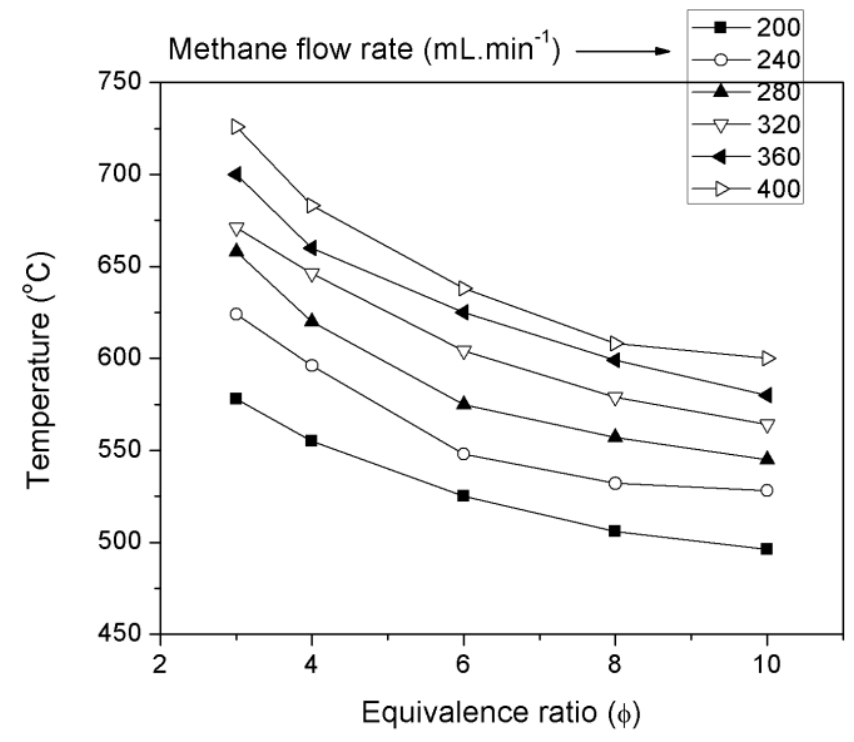

Figure 4: FFC temperatures as functions of equivalence ratio and methane flow rate 


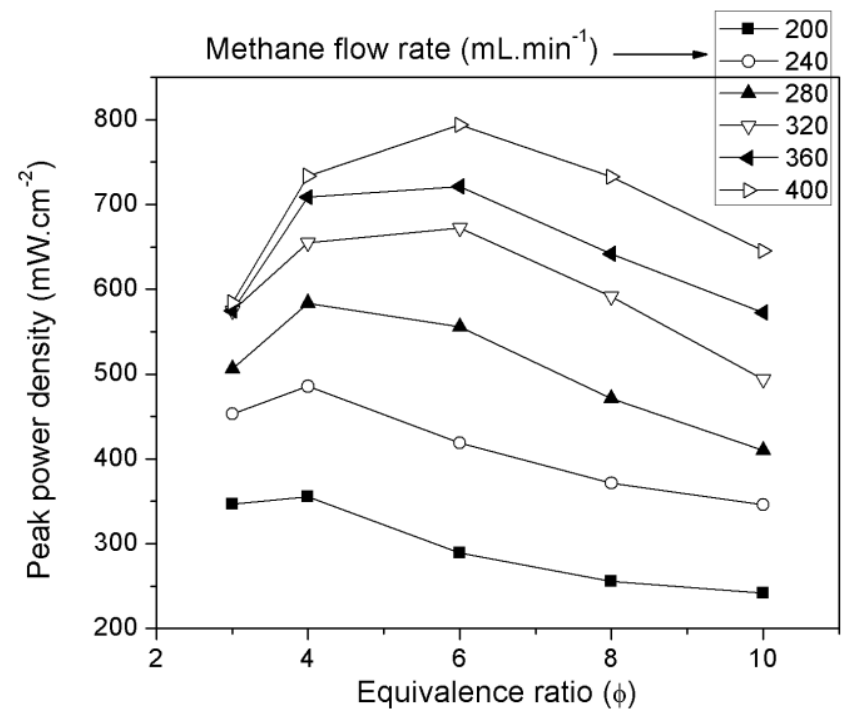

Figure 5: Peak power densities of FFC as functions of equivalence ratio and methane flow rate. 


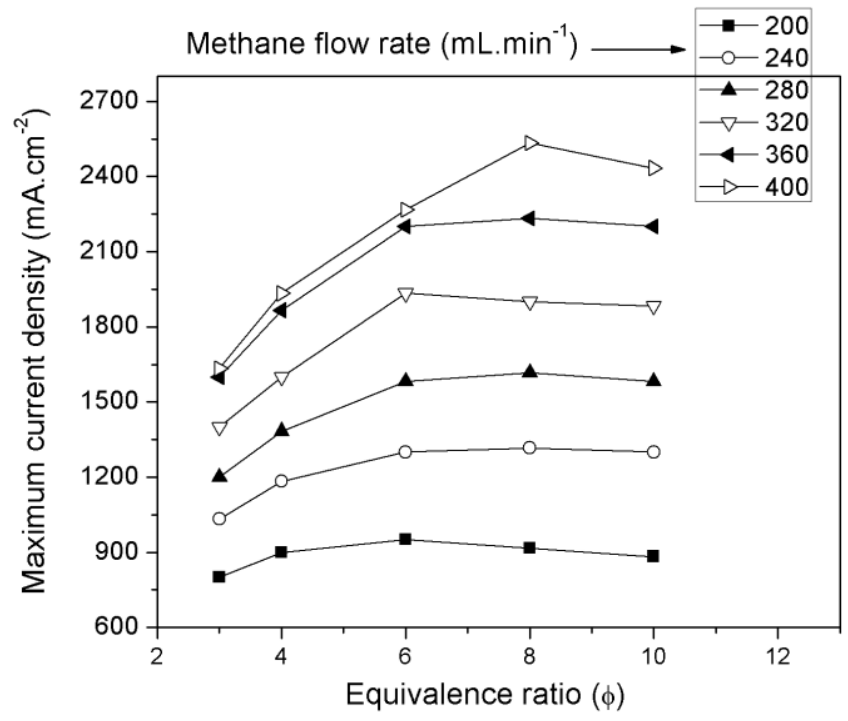

Figure 6: Peak current densities of FFC as functions of equivalence ratio and methane flow rate 


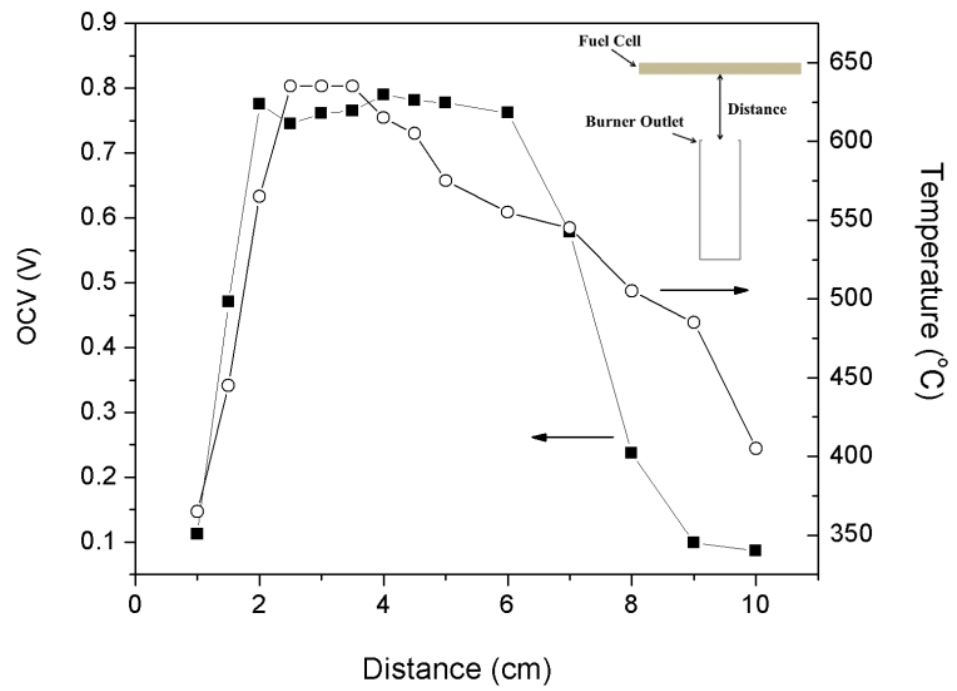

Figure 7: OCVs as a function of distance between fuel cell and burner outlet at an equivalence ratio of 6 with the methane flow rate of $400 \mathrm{~mL} \cdot \mathrm{min}^{-1}$ 


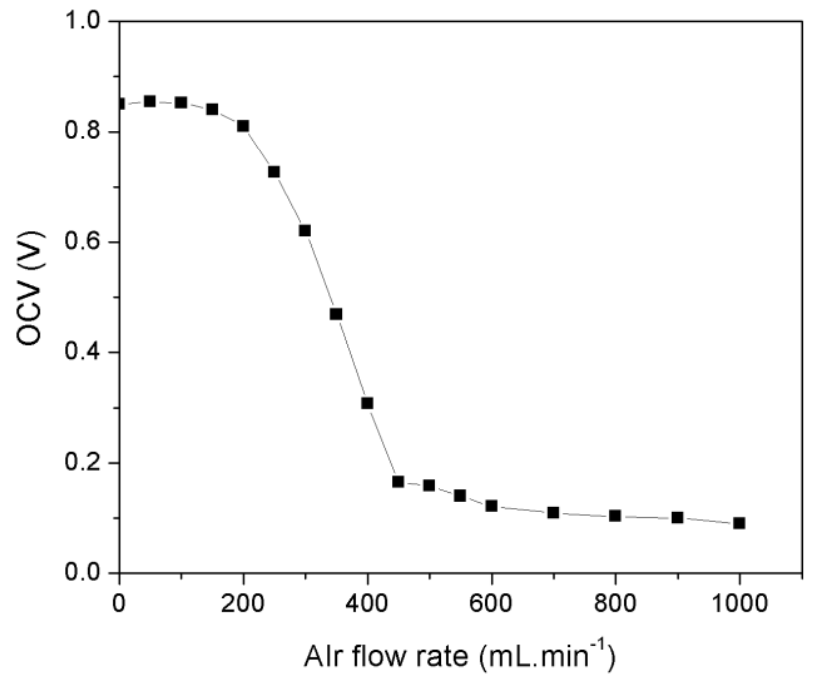

Figure 8: OCV as a function of air flow rate with a methane flow rate of 400mL.min ${ }^{-1}$. 


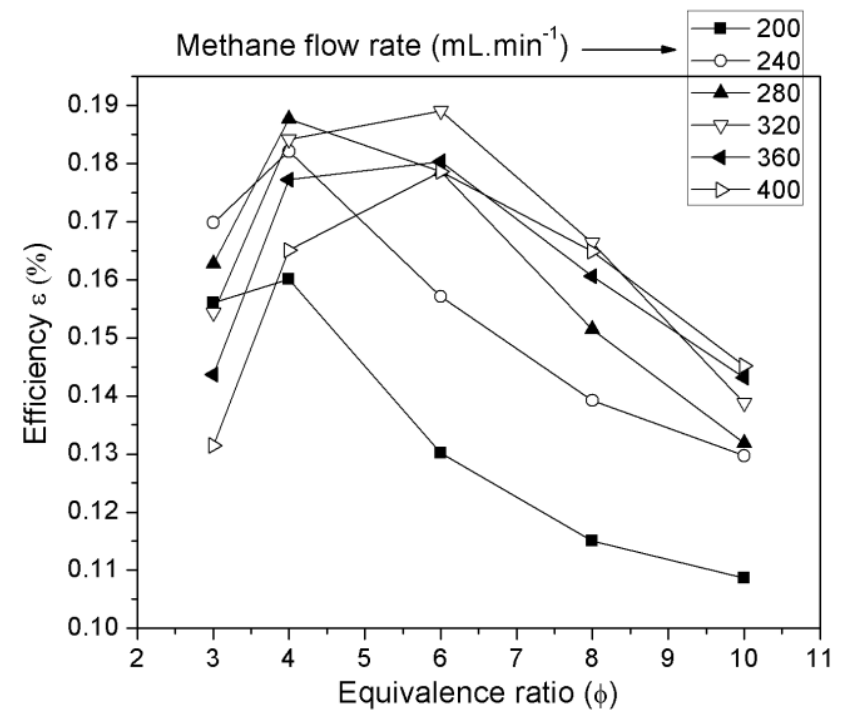

Figure 9: Electrical efficiency of FFC based on the results in Fig.6. 


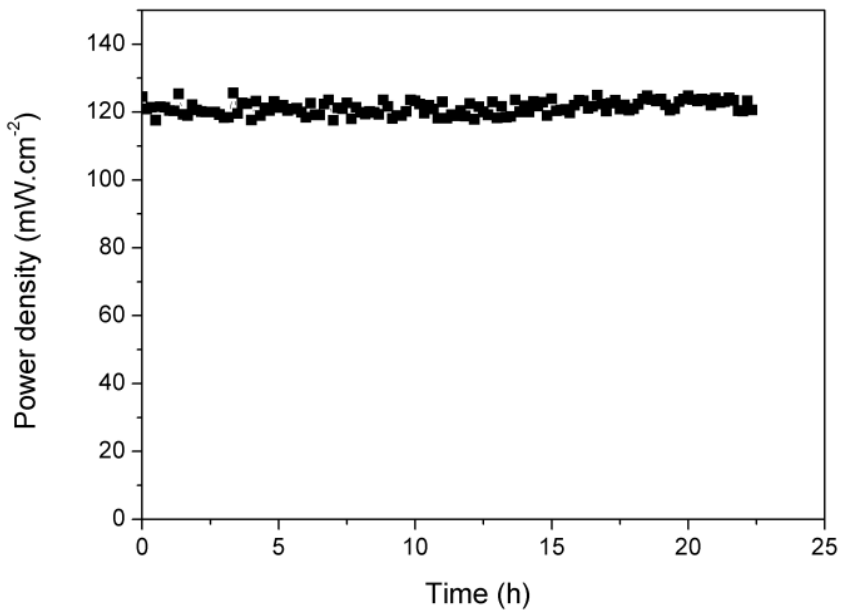

Figure 10: Short term test of FFC with a current density loading of $200 \mathrm{~mA} . \mathrm{cm}^{-2}$. 

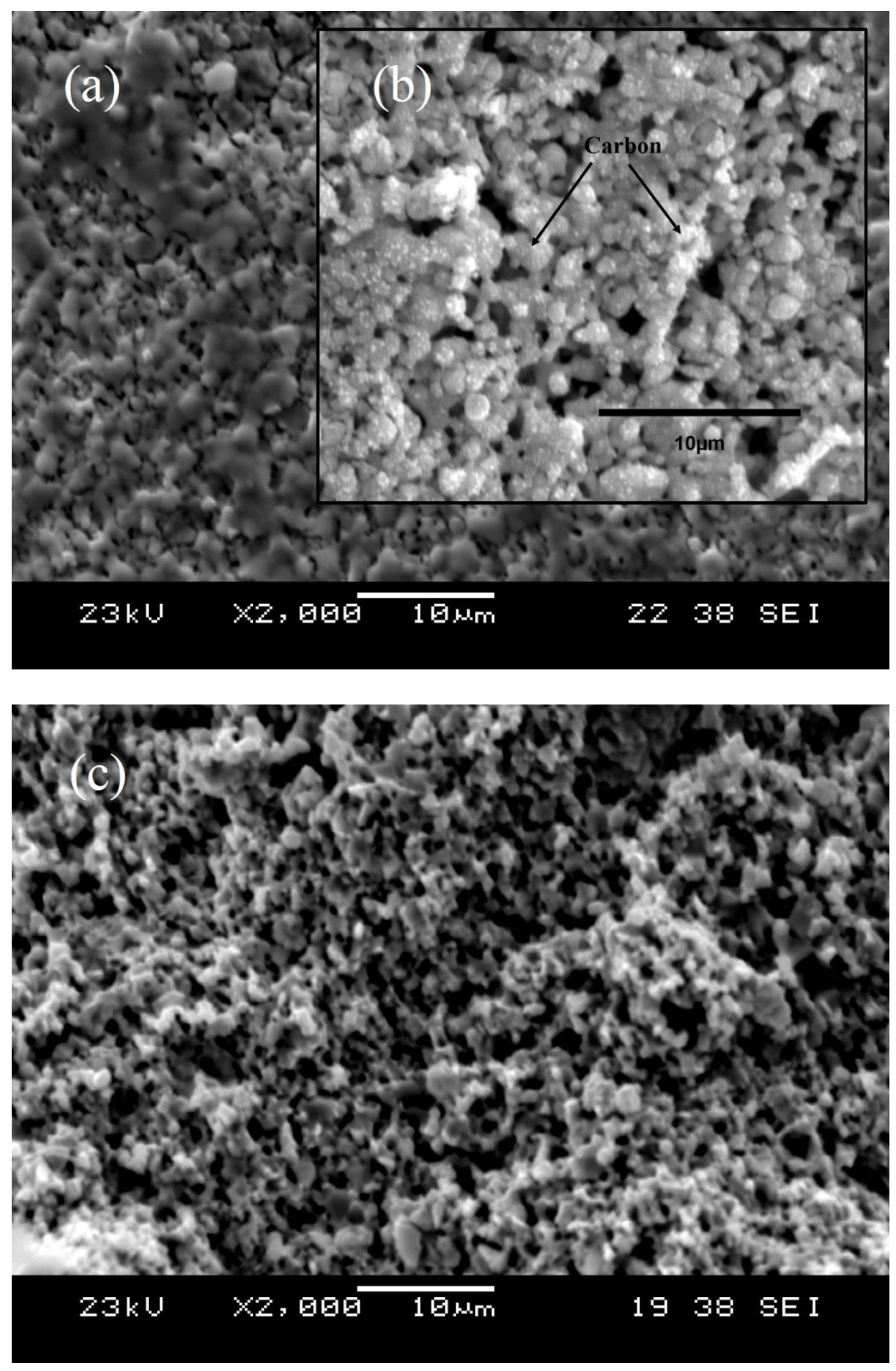

Figure 11: SEM morphologies of the anode: (a) surface before testing; (b) surface after short term testing; and (c) cross section after short term testing. 